\title{
EMPIRICAL TESTING OF NEW KEYNESIAN PHILLIPS CURVE IN CONDITIONS OF THE CZECH REPUBLIC IN $1994-2003$
}

\author{
Josef ARLT, Miroslav PLAŠIL*
}

\begin{abstract}
:
New concepts have been presented in modelling of inflation dynamics recently, among others the new Keynesian Phillips curve (NKPC). There are several traditional ways of NKPC model validity testing, but none of them seems to be practically applicable in conditions of the Czech Republic. We tried to test the validity of NKPC on the basis of time series. For this purpose we applied an interesting non-traditional method proposed by Demery and Duck. This method does not rely on direct estimation of NKPC parameters, but relatively easy tests based on the cointegration analysis of time series are employed. Its application indicates that the NKPC model cannot be considered as effective in conditions of the Czech Republic; this model does not describe the inflation process sufficiently and it is not a suitable model for inflation prediction or for the choice of appropriate monetary (antiinflation) policy.
\end{abstract}

Keywords: inflation, model, new Keynesian Phillips curve, time series, cointegration analysis

JEL Classification: E12, E31, C22

\section{Introduction}

One of the urgent problems macroeconomists are highly interested in is the nature of inflation dynamics. The understanding of the process that generates inflation, particularly in a short period, helps to define its crucial determinants and their influence. This question has been analysed intensively for a long time without being answered definitively after decades of investigation.

Recently, some new concepts have been presented in this field. They are derived from an important stream of economic thinking, from the so-called new Keynesian macroeconomics. In the eighties and nineties of the last century this economic school offered many original interpretations of economic problems, among them the

*) University of Economics, 4, W. Churchill Sq., CZ - 13067 Prague 3 (e-mail: arlt@ vse.cz; plasil@vse.cz).

${ }^{\star *}$ ) The research was supported by the grant of the GAČR No. 402/03/1292. 
problems of the relationship between inflation and dynamics of real economic activity. Theoretical aspects for modelling the relationship that could be tested empirically were described in papers of Taylor (1980), Calvo (1983) and Fisher (1997), who accentuated models of staggered nominal price setting. Their approach based on microeconomic principles of utility maximizing by forward-looking subjects was further developed and improved. An idea was formulated that aggregation over individual decisions leads to a relation that links inflation to some measure of overall economic activity ${ }^{1)}$ of a given country in a short period, similarly like in traditional Phillips curve. Therefore this relationship is somewhat loosely called new Keynesian Phillips curve. But it differs from traditional Phillips curve in its microeconomic derivation that facilitates the interpretation of structural parameters and leads to some other differences.

Such differences involve fundamental implications for appropriate conduct of monetary policy: as stated by Jondeau, Le Bihan (2001), a fully credible central bank can engineer a disinflation at no cost in terms of output if inflation is a forward-looking phenomenon, whereas lowering steady-state inflation requires a recession in the context of a traditional Phillips curve. Therefore the issue whether NKPC is empirically relevant is extremely important.

Obviously, it is not easy to test and prove this theory on real data. NKPC model implies many problems concerning mainly econometric specification of variables and method of estimation. Nevertheless, NKPC is recognised as an effective alternative to the traditional approach.

\section{Construction of New Keynesian Phillips Curve}

\section{1 Baseline Model}

To derive $\mathrm{NKPC}^{2)}$ we assume an environment of monopolistically competitive firms producing the differentiated product that face some type of constraints on price adjustment.

Following Calvo (1983) we assume that in any period any firm has fixed probability $1-\theta$ with which it can change prices in the given period, and probability $\theta$ with which it will keep its prices unchanged. The probabilities are independent of a particular firm and of the time that has elapsed from the last price revision. The fraction $1-\theta$ also shows the ratio of firms that will change their prices in the given period or the ratio of firms that will keep their prices unchanged (fraction $\theta$ ). The average time for which prices remain fixed is as follows

$$
(1-\theta) \sum_{k=0}^{\infty} k \theta^{k-1}=1 /(1-\theta)
$$

If e.g. $\theta=0.75$, prices in a model with quarterly data remain unchanged for a year on average $(1 /(1-0.75)=4)$. Hence the parameter $\theta$ expresses the degree of price rigidity: the higher its value, the longer the time for which the prices remain fixed on average.

1) Nominal marginal costs or alternatively output gap could be used as the measure. In this paper we use nominal marginal cost for empirical implementation (see Galí, Gertler, 1999, for discussion).

2) Detailed derivation is readily available elsewhere (see e.g. Jondeau, Le Bihan, 2001). 
Assume that firms are identical except for differentiated product and pricing history. Assume also the isoelastic demand function for each firm and each product.

It can be shown (see Goodfriend, King, 1997; King, Wolman, 1996; Woodford, 1996) that the logarithm of aggregate price level $p_{t}$ evolves as the weighted average mean of the logarithm of aggregate price level of the past period $p_{t-1}$ and of the logarithm of a newly established price $p_{t}^{*}$ (i.e. a price established by the firms that will change their prices in period $t$ )

$$
p_{t}=\theta p_{t-1}+(1-\theta) p_{t}^{*}
$$

Intuitively, this relation can be deduced by a simple consideration: the firms that adjust their prices in period $t$ will establish the same price $p_{t}^{*}$ because they are considered identical and solve the same price - optimizing problem. It can also be assumed that the prices of firms that remain unchanged in the given period equal the aggregate price level of the last period. The result of the pricing problem by which firms try to maximize stream of expected discounted profits is a pricing rule that is expressed by the equation

$$
p_{t}^{*}=(1-\beta \theta) \sum_{k=0}^{\infty}(\beta \theta)^{k} E_{t}\left\{\text { mcnom }_{t+k}\right\}
$$

where $\beta$ is the subjective discount factor of future profits, mcnom $_{t}$ is nominal marginal costs of the firm in period $t$ (expressed in a natural logarithm), $E_{t}$ is the expected value based on information available at time $t$.

Obviously, in the case of perfect price flexibility $(\theta=0)$ the firm establishes an optimum price proportionally to the values of the present marginal costs. If the level of price rigidity starts increasing, the firm will take into account the future expected trajectory of nominal marginal costs. The explanation is logical: the higher the level of price rigidity, the longer the time for which prices remain fixed. This is the reason why the firm adjusting its prices in period $t$ that faces the considered constraint according to which its prices will probably remain fixed in several subsequent periods will accentuate future costs more than the present ones in the course of price establishing.

Let us denote $\pi_{t} \equiv p_{t}-p_{t-1}$ the inflation rate in period $t$ and mcreal ${ }_{t}^{d}$ the percentage deviation of the firm's real marginal cost from its steady-state. By combining equations (2) and (3) an equation for the rate of inflation can be derived

$$
\pi_{t}=\lambda \text { mcreal }_{t}^{d}+\beta E_{t}\left\{\pi_{t+1}\right\}
$$

where $\lambda \equiv(1-\theta)(1-\beta \theta) / \theta$ and $\beta$ is the subjective discount factor. Obviously, $\lambda$ decreases with the level of price rigidity (with increasing parameter $\theta$ ), i.e. the small fraction of firms adjusting its prices in the given period indicates that inflation will be less sensitive to movements of real marginal costs.

It ensues from the above exposition that the firm does not attach much importance to information about the past when an optimum price is established, but only future information becomes important. Firms in NKPC model are forward-looking, so inflation in this concept is not determined by inflation inertia and fully depends on the present and future economic conditions. This constitutes an essential difference between this model and former concepts of Phillips curve.

\section{2 Hybrid Model}

Practically, the idea that there exist only forward-looking firms is not always realistic. Gertler and Galí (1999) claimed that two types of firms exist in economy: firms 
establishing their prices on the basis of rule (3) and firms that can be called backward-looking as they use information about the past behaviour of the aggregate price level for price establishing. For such a structure of firms in economy the process of price setting can be modelled in the following way. All firms can change their prices with probability $1-\theta$, but only fraction of them $1-\omega$ establishes prices according to (3). Parameter $\omega$ can be considered as a certain departure from full rationality in model (4) in favour of the traditional approach (traditional Phillips curve) when firms are backward-looking. The aggregate price level is expressed in this case by the equation

$$
p_{t}=\theta p_{t-1}+(1-\theta) \bar{p}_{t}^{*}
$$

where $\bar{p}_{t}^{*}$ is the logarithm of the price index of newly changed prices in period $t$. If the symbol $p_{t}^{f}$ denotes the price established in time $t$ by a forward-looking firm and if the symbol $p_{t}^{b}$ denotes the price established in time $t$ by a backward-looking firm, the form of this price index is as follows

$$
\bar{p}_{t}^{\star}=(1-\omega) p_{t}^{f}+\omega p_{t}^{b}
$$

It is obvious that $p_{t}^{f}$ is established in the same way as in the original model, i.e. according to equation (3). Under condition that the backward-looking firm applies only the information about inflation rate in period $t-1$ to establish a new price at time $t$ and that no firm can say about any other competitor firm whether it is forward or backward-looking, it holds for $p_{t}^{b}$ that

$$
p_{t}^{b}=\bar{p}_{t-1}^{\star}+\pi_{t-1}
$$

The backward-looking firm will establish its price at time $t$ as the price from the most recent round of price adjustment, with a correction for inflation. Backward-looking firms observe how prices were established in the past period and when establishing their price, they adjust it for inflation while this adjustment is based on the knowledge of past values.

A hybrid model can be derived by combining equations (5) to (7)

$$
\pi_{t}=\gamma_{b} \pi_{t-1}+\gamma_{t} E_{t}\left\{\pi_{t+1}\right\}+\lambda \text { mcreal }_{t}^{d}
$$

where $\lambda \equiv(1-\omega)(1-\theta)(1-\beta \theta) \phi^{-1}, \gamma_{f} \equiv \beta \theta \phi^{-1}, \gamma_{b} \equiv \omega \phi^{-1}$ and $\phi=\theta+\omega[1-\theta(1-\beta)]$.

The coefficients of model (8) depend on three parameters again: $\theta$ - level of price rigidity, $\omega$ - fraction of backward-looking firms and $\beta$-subjective discount factor. NKPC model (4) and traditional Phillips curve are two limit cases of hybrid model (8).

\section{Cointegration-based Test of Validity of Basic New Keynesian Phillips Curve Model}

There are several ways of testing NKPC model validity. Estimation and tests of its parameters are a traditional procedure. Both in basic model (4) and in hybrid model (8) the present rate of inflation depends on the expected future rate of inflation $E_{t}\left\{\pi_{t+1}\right\}$. If the time series of inflation expectations obtained by sampling surveys are available, a standard estimation technique can be used. Inflation expectations have been monitored in the USA for a long time, so necessary time series are commonly available. But these time series are too short in the euro area, and they are still shorter in the Czech Republic. In case no time series of inflation expectations are available or if they are not applicable because they are unstable and too short, e.g. Generalised Method of Moments (GMM) can be used for estimation of 
parameters (see e.g. Hansen and West, 2002). This method currently becomes quite popular worldwide for the estimation of NKPC model. Its deficiency is that it is rather sensitive to the choice of the so called instrumental variables (e.g. inflation rate, production gap, marginal costs and interest rates spread).

Facing these difficulties the paper of Demery and Duck (2002) is very interesting because it proposes a non-traditional method of NKPC validity testing. This method does not rely on direct estimation of NKPC parameters, but relatively easy tests are used that are based on the cointegration analysis of time series, and it does not require any explicit knowledge of future expected rates of inflation. From this aspect the method seems practically applicable in conditions of the Czech Republic. Now we will describe this method in brief. Let us return to equation (3), which expresses an optimizing rule to establish a new price $p_{t}^{*}$ by firms that can change their price in the given period $t$. The equation can be re-written as

$$
p_{t}^{*}=\text { mcnom }_{t}+\sum_{k=0}^{\infty}(\beta \theta)^{k} E_{t} \Delta\left\{\text { mcnom }_{t+k}\right\}
$$

Equation (9) shows that if mcnom $_{t}$ is an integrated time series of order one (i.e. I(1)), then $p_{t}^{*}$ is also an integrated time series of order one and $\operatorname{mcnom}_{t}$ and $p_{t}^{*}$ are cointegrated with a cointegration vector $[1-1]$. It follows that the vector $x_{t} \equiv\left[\right.$ mcnom $\left._{t} p_{t}^{*}\right]$ can be expressed as a error correction model (EC model), i.e. in a form

$$
B(L) \Delta x_{t}=-\rho S_{t-1}+a_{t}
$$

where $S_{t} \equiv p_{t}^{*}-$ mcnom $_{t}, \Delta x_{t}=\left[\Delta \text { mcnom }_{t} \Delta p_{t}^{*}\right]^{\prime} ; B(L)$ is the square polynomial (2x2) matrix of order $q-1 ; \rho$ is the column vector with two elements, at least one of them is non-zero and $a_{t}$ denotes the vector of white noise error terms.

This system can be rearranged to a VAR model of order $q$ in the vector $[\Delta m c$ nom $\left._{t} S_{t}\right]^{\prime}$, i.e.

$$
G(L)\left[\begin{array}{c}
\Delta \text { mcnom }_{t} \\
S_{t}
\end{array}\right]=u_{t}
$$

where $G(L)$ is the polynomial matrix of order $q$ in which the coefficients on $\Delta m c$ $n^{n} m_{t-q}$ equal zero and $u_{t} \equiv\left[u_{1 t} u_{2 t}\right]^{\prime}$ is the vector of white noise errors. It is useful to convert equation (11) to a form

$$
Z_{t}=A Z_{t-1}+v_{t}
$$

where $Z_{t}=\left[\Delta \text { mcnom }_{t}, \ldots, \Delta \text { mcnom }_{t-q+1}, S_{t}, \ldots, S_{t-q+1}\right]^{\prime}, v_{t}=\left[u_{1 t}, 0, \ldots, 0, u_{2 t}, 0, \ldots, 0\right]^{\prime}$ and $A$ is the $2 q \times 2 q$ matrix (the representation of EC means the restriction $\alpha_{11 q}=$ $\alpha_{21 q}=0$ )

$$
A=\left[\begin{array}{llllllllll}
\alpha_{111} & \alpha_{112} & \ldots & \alpha_{11 q-1} & \alpha_{11 q} & \alpha_{121} & \alpha_{122} & \ldots & \alpha_{12 q-1} & \alpha_{12 q} \\
1 & 0 & \ldots & 0 & 0 & 0 & 0 & \ldots & 0 & 0 \\
\vdots & \vdots & & \vdots & \vdots & \vdots & \vdots & & \vdots & \vdots \\
0 & 0 & \ldots & 1 & 0 & 0 & 0 & \ldots & 0 & 0 \\
\alpha_{211} & \alpha_{212} & \ldots & \alpha_{21 q-1} & \alpha_{21 q} & \alpha_{221} & \alpha_{222} & \ldots & \alpha_{22 q-1} & \alpha_{22 q} \\
0 & 0 & \ldots & 0 & 0 & 1 & 0 & \ldots & 0 & 0 \\
\vdots & \vdots & & \vdots & \vdots & \vdots & \vdots & & \vdots & \vdots \\
0 & 0 & \ldots & 0 & 0 & 0 & 0 & \ldots & 1 & 0
\end{array}\right]
$$


It follows from equation (12) that

$$
E\left[Z_{t+k} \mid H_{t}\right]=A^{k} Z_{t}
$$

where $H_{t}$ is the information available to the firm that contains current and lagged values of variables in VAR model.

The following relation is deduced from equation (9)

$$
S_{t} \equiv p_{t}^{*}-\text { menom }_{t}=\sum_{k=1}^{\infty}(\beta \theta)^{k} E_{t} \Delta \text { mcnom }_{t+k}
$$

and by combining this equation with equation (13) we get

$$
S_{t}=\sum_{k=1}^{\infty}(\beta \theta)^{k} h^{\prime} A^{k} Z_{t}=h^{\prime} \beta \theta A[I-\beta \theta A]^{-1} Z_{t}, \text { where } h=[1,0,0, \ldots, 0]^{\prime}
$$

According to the definition $S_{t}=g^{\prime} Z_{t}$, where $g^{\prime}$ selects the $(q+1)$-th row of $Z_{t}$, NKPC model leads to restrictions on the matrix $A$ that can be expressed as follows

$$
g^{\prime}[I-\beta \theta A]=h^{\prime} \beta \theta A
$$

or as $\alpha_{111}=-\alpha_{211}, \alpha_{112}=-\alpha_{212}, \ldots, \alpha_{11 q}=-\alpha_{21 q}$, and $1-\beta \theta \alpha_{121}=\beta \theta \alpha_{221}, \alpha_{122}=-\alpha_{222}, \ldots, \alpha_{12 q}=$ $-\alpha_{22 q}$. Obviously, one of the ways of testing the NKPC model validity is to estimate parameters of model (12) and to test whether restrictions (14) hold.

An alternative and simpler form of this test can be derived from the difference of equation (2) that leads to the equation for inflation rate

$$
\pi_{t}=(1-\theta) \Delta p_{t}^{*}+\theta \pi_{t-1}
$$

Because $\Delta p_{t}^{*}=\Delta$ mcnom $_{t}+S_{t}-S_{t-1}$, the relation

$$
\pi_{t}=(1-\theta)\left[\Delta \text { mcnom }_{t}+S_{t}\right]-(1-\theta) S_{t-1}+\theta \pi_{t-1}
$$

holds.

VAR model (12) and restrictions (14) result in the equation

$$
\Delta \text { mcnom }_{t}+S_{t}=\frac{1}{\beta \theta} S_{t-1}+\left(u_{1 t}+u_{2 t}\right)
$$

its substitution into equation (16) gives the model

$$
\pi_{t}=\frac{(1-\beta \theta)(1-\theta)}{\beta \theta} S_{t-1}+\theta \pi_{t-1}+(1-\theta)\left(u_{1 t}+u_{2 t}\right)
$$

According to NKPC model the rate of inflation should be the function of one-period lagged values of the error correction term and of its own one-period lagged values. Estimates of parameters at other lags of inflation (several-period lags) or at any other lagged variable should be statistically insignificant. So, simple $t$-test (or $F$-test) of significance for other variables in equation (18) is an alternative test of NKPC model validity.

Before any of the proposed tests can be carried out, it is necessary to deduce the error correction term $S_{t}$. The substitution of the relation $S_{t} \equiv p_{t}^{*}-$ mcnom $_{t}$ in equation (2) for $p_{t}^{\star}$ makes it possible to convert it to

$$
p_{t}=(1-\theta)\left(S_{t}+\text { mcnom }_{t}\right)+\theta p_{t-1}=(1-\theta) \text { mcnom }_{t}+\theta p_{t-1}+(1-\theta) S_{t}
$$

If the value of parameter $\theta$ were known, $S_{t}$ could be calculated directly from equation (19). Foreign studies mostly dealing with American economy, and also with the 
economy of some European countries (Great Britain, Norway), coincide in the opinion that price changes have about a yearly frequency, that means the value of parameter $\theta$ is approximately ${ }^{3}$ 0.75. As far as the authors of this study know, no such considerations exist in the Czech Republic, therefore an alternative procedure should be used and parameter $\theta$ must be estimated. The estimation is made in regression equation (19), from which the error correction term (i.e. $S_{t}$ ) is omitted. $\hat{S}_{t}$ is obtained as the time series of residuals of this regression equation divided by the estimation of the parameter at mcnom $_{t}$.

\section{Empirical Analysis}

\section{1 Data}

When estimating parameters of econometric models in the Czech Republic, besides traditional problems of specification of variables we face other problems concerning especially the quality of applicable data. Since the early nineties the Czech Republic (former Czechoslovakia) underwent a complicated transformation process from central planning to market economy, and this process had a crucial influence on all examined economic indicators. Transition to market economy and splitting of Czechoslovakia caused the physical discontinuity of indicators. The time series after 1989 and/or after 1993 cannot be considered as a mere continuation of preceding statistical data because they are determined by the effects of other economic factors. As a consequence, data for a relatively short time segment are available for the testing of NKPC model (and other models as well).

The transformation process was not free of complications either. During transition to a market economy central authorities had to take some necessary measures that largely influenced the operation of economy. By exerting a strong and decisive influence on the operation of economy (on macroeconomic indicators) the role of other agents (firms, individuals) was suppressed. Let's note that NKPC model is based on their maximizing of utility. Their influence can become stronger after the economy has stabilised to some extent, when the government does not intervene into economy radically any longer, say, it has been so in conditions of the Czech Republic in several recent years. If we are aware of this fact, further shortening of time series should be done (but it is impossible from the aspect of the estimation). It can also be disputable to define the year from which the time series can be considered stable with regard to government interventions.

Last but not least, we face some technical problems. After the Czech Republic opened its economy to the surrounding world, new statistical standards of indicators measurement had to be adopted. The adoption of new standards harmonised with advanced Europe is not easy and it requires much experience and time. This process implies such problems as the adoption of new methodology of GDP quantification which means that older data are not fully comparable with new data, or the frequency of recording and measuring of some variables (and/or detail in classification of some indicators). Although nowadays the quality of provided services is undoubtedly much higher than in the early nineties, even at present some of our own indicators have to be constructed if necessary. It is to note that these constructed indicators are only of approximate nature.

3) In some papers a lower value is given, most frequently it ranges between 0.5 and 0.75 . 
Specifically, model (4) and/or model (8) contain two types of directly unmeasurable variables. These are (nominal and real) marginal costs and expectations of future inflation on the basis of information available at time $t$. Even though "actual" inflation expectation found out by a sampling survey in firms can basically be substituted for inflation expectation, this procedure is not very usual; expectations are a problem of special procedures and special estimation techniques.

We exploit the assumption of Cobb-Douglas production function with constant returns to scale (i.e. $\alpha_{k}+\alpha_{n}=1$ ) to obtain a measure for marginal costs. If $A_{t}$ is the level of technology, $K_{t}$ and $N_{t}$ are the used factors of production: capital and labour, respectively, the output (production) is given by the equation

$$
Y_{t}=A_{t} K_{t}^{\alpha} \alpha_{t}^{\alpha_{n}}
$$

Nominal marginal costs are given by the equation $W_{t} /\left(\partial Y_{t} / \partial N_{t}\right)=W_{t} N_{t} / \alpha_{n} Y_{t}$, where $W_{t}$ is the nominal wage rate. That means marginal costs are calculated as the ratio of wage rate to marginal product of labour. ${ }^{4}$ As in equation (3) nominal marginal costs are expressed in the logarithm, after simple adjustment we get the following equation

$$
\text { mcnom }_{t}=\ln \left(\frac{W_{t} N_{t}}{Y_{t}}\right)-\ln \left(\alpha_{n}\right)
$$

Under constant returns to scale the constant $\alpha_{n}$ is a number from the interval $(0 ; 1)$ while it ranges approximately from 0.5 to 1 in different economies (Hájek and Bezděk, 2000, estimated the value of this parameter for the Czech Republic for 1995 1998 to be 0.481 ). In case $\alpha_{n}$ approaches 1 , the value of the second term in equation (21) is negligible and can be omitted. In addition, in the first differences of the series mcnom $_{t}$ that will be used below this term will drop out. Assume the following equation

$$
\text { mcnom }_{t}=\ln \left(\frac{W_{t} N_{t}}{Y_{t}}\right)
$$

the term in brackets that shows total compensation of employees to total production is sometimes called unit labour costs or labour costs per unit production.

Now we can proceed to empirical specification of particular indicators. ${ }^{5}$ All data were provided by the Czech Statistical Office (CSO) and cover the period 1994:Q1 - 2003:Q2.

The CSO publishes unit labour costs once a year and they are defined as the ratio of full labour costs (FLC) to labour productivity per employee; this productivity is defined as the ratio of GDP to total employment. ${ }^{6)}$ The CSO defines full labour costs as consisting of wage costs (including wage compensations), social costs and expenditure, and other social emoluments, employees' training, etc. Unfortunately, the yearly frequency of FLC is not sufficient for our study, so we had to use an alternative specification making it possible to generate a quarterly time series.

For the needs of this study nominal marginal costs (unit labour costs) can be defined by this equation

4) For a more detailed derivation see Gertler's lecture (http://econ.bu.edu/gilchrist/teaching/ec702/lecture84.pdf).

5) The same symbols will be used.

6) It coincides with the bracketed term in equation (21) because it can be converted very easily to the form $W_{t} /\left(Y_{t} / N_{t}\right)$. 


$$
\text { mcnom }_{t}=\ln \left\{\mathrm{FLC}_{t} /\left(\mathrm{GAV}_{\mathrm{f}} / \mathrm{TEMP}_{t}\right)\right\}
$$

where the basis for the series of full labour costs FLCm is the quarterly nominal gross wage (seasonally adjusted) that accounts for the largest proportion of FLC. GAV95 is gross value added in constant prices of the year 1995 (seasonally adjusted by the CSO) and TEMP is average total employment (seasonally adjusted - our own adjustment) determined by a sampling survey. The CSO monitors this proportion only for a period of one year, but it is realistic to assume that this proportion does not vary very much during the year and is approximately constant. In the Czech Republic this proportion is about $70 \%$ in particular years. FLCm are calculated by dividing the quarterly nominal gross wage by its proportion in FLC in the given year. GAV is in current prices - this macroaggregate is often preferred to GDP to eliminate the influence of taxes and subsidies.

Price index $p_{t}$ is defined as the logarithm of GAV deflator

$$
p_{t}=\ln \left(\mathrm{GAV}_{t} / \mathrm{GAV} 5_{t}\right)
$$

and inflation is

$$
\pi_{t}=p_{t}-p_{t-1}
$$

Figure 1

Price Index and Nominal Marginal Costs ${ }^{1)}$

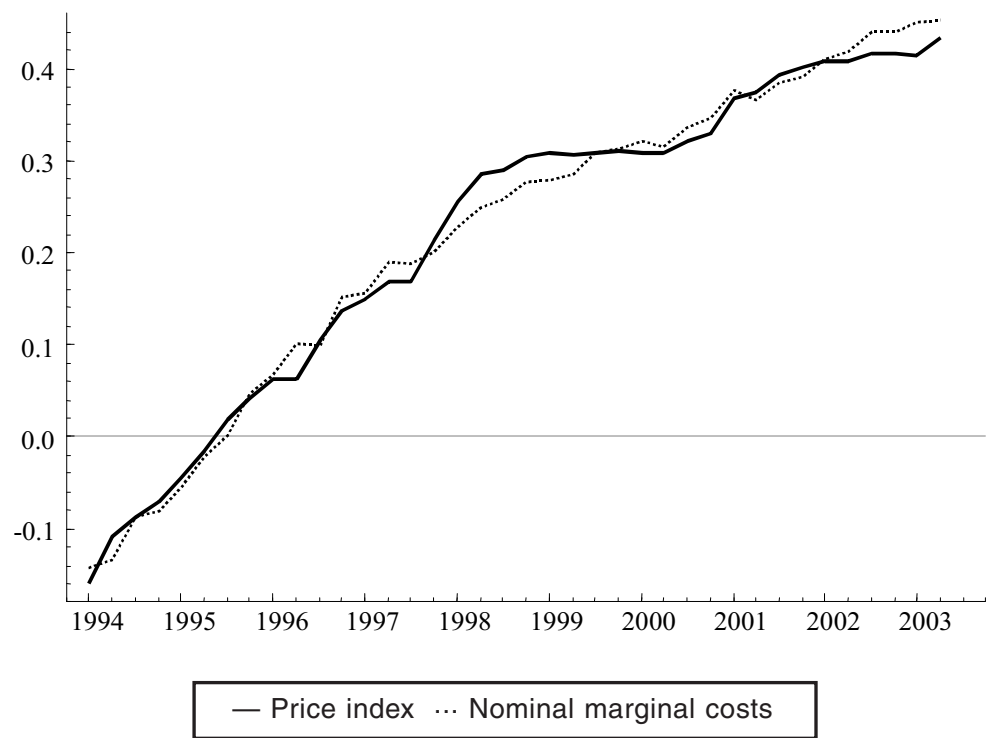

1) Level and variability rearranged with respect to price index. 
Figure 2

Inflation Rate and the Difference of Nominal Marginal Costs

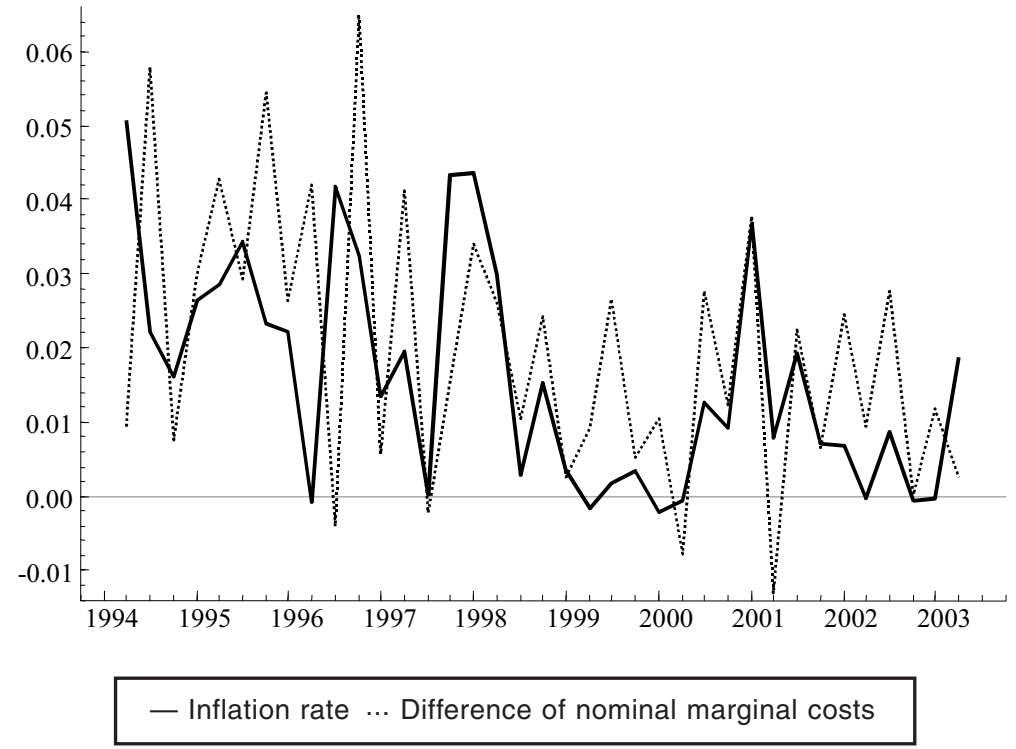

\section{2 Empirical Testing of Hypothesis}

Figure 1 shows that the time series of nominal marginal costs and price index are non-stationary. Augmented Dickey-Fuller test indicates that the hypothesis that both time series are I(1) cannot be rejected. Figure 2 shows the first differences of both time series; their course is obviously similar. If the time series of nominal marginal costs and price index were of type I(1), their first differences would have to be stationary time series. But Figure 2 documents a trend of a slight decrease in their values. In these circumstances the use of Dickey-Fuller test for stationarity testing need not to be suitable because the strength of this test is not high enough to prove the so-called fractional stationarity. A more suitable procedure is to estimate fractional parameter $d$ from model $\mathrm{FI}(d)$ for differenced time series (see e.g. Arlt, Arltová, 2003). Because the estimation is smaller than 0.5 in both cases, it is to state that the time series of differences are fractionally stationary, i.e. the original non-differenced time series can be taken as time series of type I(1).

The least-squares method is used to estimate the parameters of model (19) [without the term $\left.(1-\theta) S_{t}\right]$, the estimated model takes this form

$$
p_{t}=0.3198+0.7302 p_{t-1}+0.1836 \text { mcnom }_{t}
$$

As follows from equation (19), the sum of parameters at $p_{t-1}$ and mcnom $_{t}$ should equal 1 . The estimated model indicates that the sum of estimations of these parameters after rounding off is 0.914 , which is a number close to 1 .

Let us notice the coincidence of the estimate of parameter $\theta$ (parameter at $p_{t-1}$ ) from equation (26) with the value about 0.75 , which is often given in foreign studies. It follows from equation (1) that in our conditions prices are fixed for four periods on average, i.e. prices do not change for one year on average. An equivalent conclusion is that about $25 \%$ of firms change their prices in each period. 
The error correction term, i.e. $\hat{S}_{t}$, is estimated by dividing the residuals from model $(26)$ by the value $(1-\hat{\theta})=0.1836$. This time series is shown in Figure 3 . By augmented Dickey-Fuller test it was proved to be stationary (in agreement with theoretical assumptions).

Figure 3

Estimation of the Component Error Correction

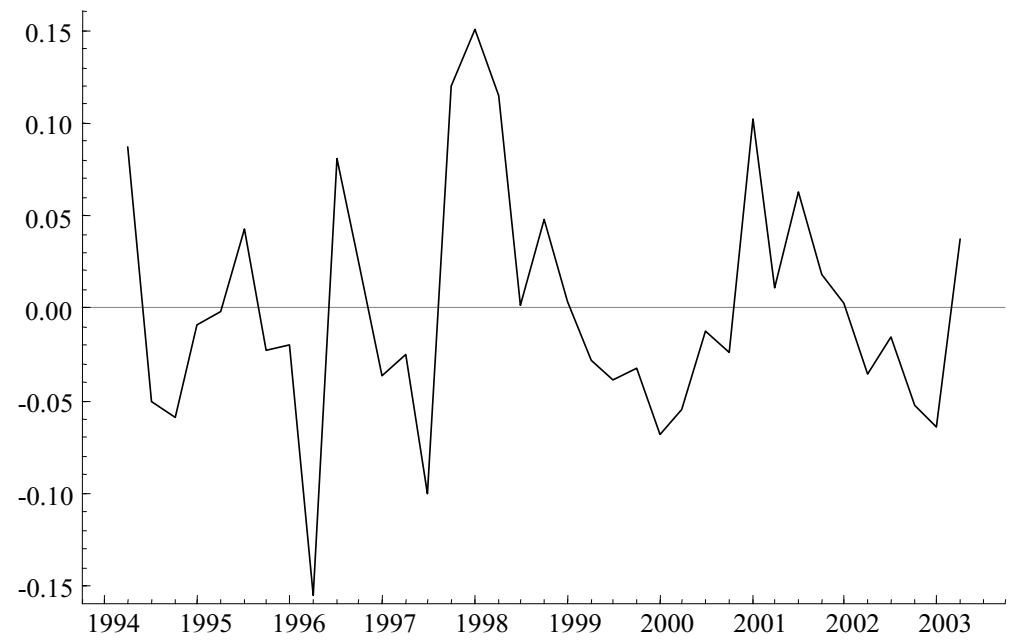

Empirical verification of the validity of model (18) will test the effectiveness of the basic NKPC model in conditions of the Czech Republic. The model should comprise only statistically significant estimations of parameters at the error correction component lagged by one quarter and inflation rate lagged by one quarter, estimates of parameters at other explanatory variables should be statistically insignificant:

$$
\begin{gathered}
\pi_{t}=0.925 \pi_{t-1}-0.163 \hat{S}_{t-1} \\
\pi_{t}=1.338 \pi_{t-1}-0.224 \hat{S}_{t-1}-0.321 \Delta \text { mcnom }_{t-1}
\end{gathered}
$$

Model (27) is an estimation of inflation equation (18) without any other explanatory variables (PcGive diagnostic tests are used). Neglecting the fact that the estimate of parameter $\theta$ is now by about two tenths higher than that from model (26), the estimate of parameter $\beta$ is unreal. It follows from the basic formulation of NKPC model that the value of this parameter is to be positive, but our estimation is -0.54 . The negative value of this parameter estimate implies a negative estimate of the parameter at $\hat{S}_{t-1}$, which also contradicts the assumptions of NKPC model. It can be derived from these results that NKPC model in its basic form is not a suitable model for inflation dynamics of the Czech Republic. These results are also confirmed by model (28), which comprises the series of the first differences of nominal marginal costs $\Delta$ mcnom $_{t-1}$ as another explanatory variable (PcGive diagnostic tests are used). The estimate of the parameter at this variable is statistically significant and inflation is apparently the function of more variables than assumed by NKPC model in its basic form. 
It is to state from the above analysis that NKPC model cannot be considered as effective in conditions of the Czech Republic. This model does not describe the inflation process sufficiently; neither it is a suitable model for inflation prediction in conditions of this country nor a suitable strategic tool for the choice of optimum economic (anti-inflation) policy.

\section{Conclusion}

We tried to test the validity of new Keynesian Phillips curve on the basis of time series of the Czech Republic. For this purpose we applied an non-traditional method proposed by Demery and Duck. This method does not rely on direct estimation of NKPC parameters, but tests based on the cointegration analysis of time series are employed. It appears practically applicable also in conditions of the Czech Republic. Its application indicates that the NKPC model cannot be considered as effective in conditions of the Czech Republic; this model does not describe the inflation process sufficiently and it is not suitable for inflation prediction or for the choice of appropriate monetary (anti-inflation) policy. This conclusion is in agreement with those foreign papers that point out to bad empirical support to the theory of NKPC model. In this context Mankiw (2001) states that even though NKPC model "has many virtues, it has also one striking vice: it is completely at odds with the facts". But this statement may be too strict because even in foreign literature there are several noticeable exceptions in which the effectiveness of this model was confirmed and the influence of forward-looking firms on price setting (and consequently on the inflation process) was accentuated. If this problem has not been resolved in other countries yet, it cannot be so in this country and this study cannot give a final verdict on NKPC validity in the Czech Republic. Although its conclusions are negative from the aspect of NKPC validity, this problem should be studied further and also the model should be estimated by other estimation techniques as it was suggested in the introduction.

In the Czech Republic such estimation is complicated by its specific position and historical circumstances. A small open economy requires a specific approach to modelling. In fact, there may be large differences between small open economies that are caused by geographic position, types of foreign relations, level of development, and social and cultural aspects. Therefore the formulation of general theory is rather difficult. The complications that have arisen from specific historical circumstances involve short time series and their quality, and the demanding transition from central planning to market econom. These can explain why firms are not able to make full use of all available information for profit maximization and why an adaptive approach to the formation of inflation expectations is more perceptible in the Czech economy.

To overcome these difficulties will require some time, hence the study of this widely discussed problem should continue. If the new Keynesian Phillips curve, either its basic or hybrid form, were found a relevant model, fields of its application would be an urgent issue. It would be particularly inflation prediction and its use as a tool of monetary policy.

Even though the validity of the examined model cannot be confirmed unambiguously in general, in advanced countries the model has been examined systematically in the last years and it is an important alternative to traditional models of inflation. In the Czech Republic, this model should have a similar position and its analysis should go on. 
References

Arlt, J. (1999), Modern Methods of Time Series Modelling (in Czech). Prague: Grada Publishing.

Arlt, J., Arltová, M. (2003), Financial Time Series (in Czech). Prague: Grada Publishing.

Ball, L., Romer, D. (1990), "Real Rigidities and the Non-neutrality of Money." Review of Economic Studies, pp. 183-204.

Calvo, G. A. (1983), "Staggered Prices in a Utility Maximazing Framework." Journal of Monetary Economics, 12, pp. 383-398.

Clarida, R., Galí, J., Gertler, M. (1999), "The Science of Monetary Policy: A New Keynesian Perspective." Journal of Economic Literature, 37(4), pp. 1661-1707.

CSO (2002), Statistical Yearbook of the Czech Republic 1994. Prague: Czech Statistical Office, www.czso.cz.

Demery, D., Duck, N. (2002), "Cointegration-based Tests of the New Keynesian Model of Inflation." Bristol, University of Bristol Discussion Paper No. 02/54.

Fisher, S. (1997), "Long-term Contracts, Rational Expectations, and the Optimal Money Supply Rule." Journal of Political Economy, 85, pp. 163-190.

Galí, J. et al. (2001), "European Inflation Dynamics.“ European Economic Review, 45(7), pp. 12371270.

Galí, J., Gertler, M. (1999), "Inflation Dynamics: A Structural Econometric Analysis." Journal of Monetary Economis, 44, pp. 195-222.

Gertler, M. (2002), "Macroeconomic Theory I.“ Lecture No. 8 at New York University, Autumn.

Godfriend, M., King, R. (1997), "The New Neoclassical Synthesis and the Role of Monetary Policy." Cambridge, MA, NBER Macroeconomics Annual.

Hájek, M., Bezděk, V. (2000), "Potential Product and Output Gap Estimation in the Czech Republic" (in Czech). Prague, The Czech National Bank Working Paper No. 26.

Hansen, B. E., West, K. D. (2002), "Generalized Method of Moments and Macroeconomics." Journal of Business \& Economic Statistics, pp. 460-469.

Jondeau, E., Le Bihan, H. (2001), "Testing for a Forward-looking Phillips Curve: Additional Evidence from European and US Data." Paris, Banque de France Working Papers NER No. 86.

King, R. G., Wolman, A. L. (1996), "Inflation Targeting in a St. Louis Model of the 21st Century." Cambridge, MA, NBER Working Paper No. 5507.

Lindé, J. (2002), "Estimating New Keynesian Phillips Curves: A Full Information Maximum Likelihood Approach." Stockholm, Sveriges Riksbank Working Paper Series No. 129.

Mankiw, N. G. (2001), "The Inexorable and Mysterious Trade-off between Inflation and Unemployment.“ Economic Journal, 111, pp. C45-C61.

Plašil, M. (2003), "New Keynesian Phillips Curve in the Czech Republic." Prague, University of Economics Master Thesis.

Roberts, J. M. (2001), "How Well Does the New Keynesian Sticky-Price Model Fit the Data?" Board of Governors of the Federal Reserve System, Finance and Econometric Discussion Series 20002013.

Sbordone, A. M. (2001), "An Optimizing Model of U.S. Wage and Price Dynamics." Mimeo, Rudgers University Working Paper No. 10/2001.

Taylor, J. B. (1980), "Aggregate Dynamics and Staggered Contracts." Journal of Political Economy, 88, pp. 1-23.

Woodford, M. (1996), "Control of the Public Debt: A Requirement for Price Stability?" Cambridge, MA, NBER Working Paper No. 5684. 